\title{
إساءة استخدام الموظف العام للمركبات الحكومية
}

Doi: $10.23918 /$ ilic2020.07

م. مريم محمد أحمد

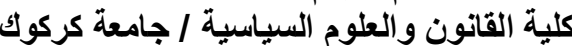

Maryammohammed1978@gmail.com
.د. ع. عامر عاشور عبد الله.

كلية القانون والعلوم السباسية / جامعة كركوك

Law_magazine@yahoo.com

\section{المقدمة}

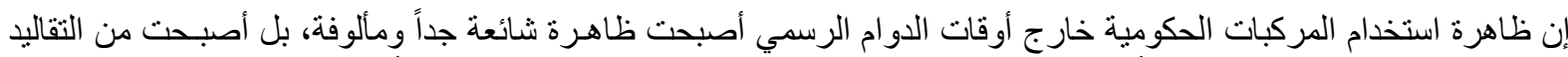

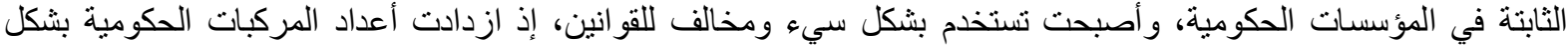

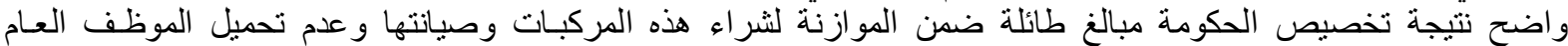

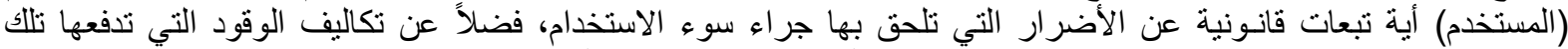

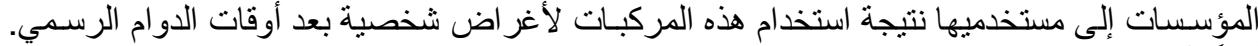

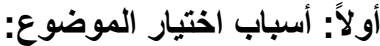

1- انتشار هذه الظاهرة بشكل غير طبيعي وما يترتب عليه من هدر للمال العام بسبب استخدامها لأغر اض شخصية خارج

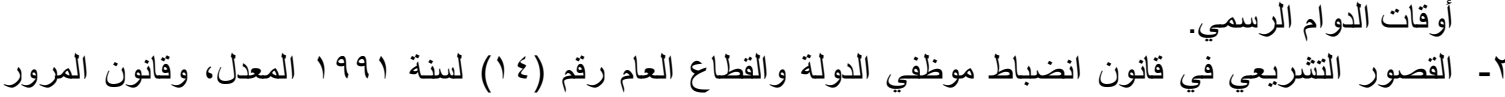

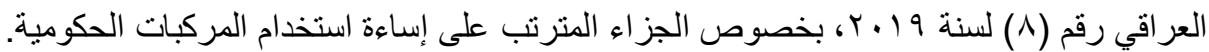

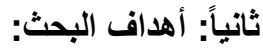

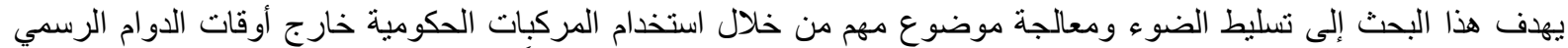

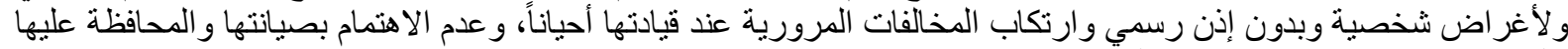

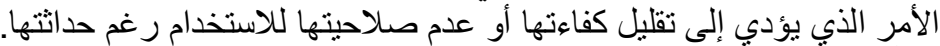

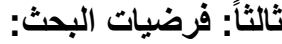

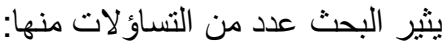

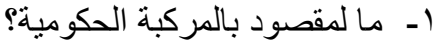

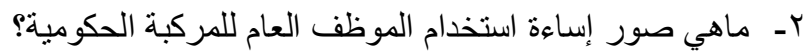
r- هل أن العقوبة المنصوص علئها في قانون انضباط موظفي الدولة انضباط موظفي الدولة والقطاع العام رقم (ع () لسنة

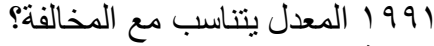

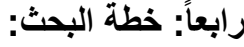

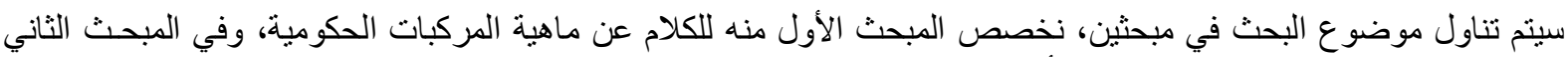

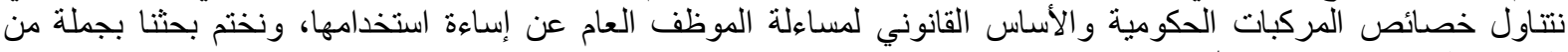

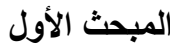

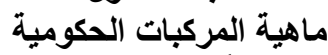

يقتضي البحث في ماهية المركبات الحكومية أن نعرفها أولاً، ومن ثم نميز بينها وبين المركبات غير الحكومية، وهو ما سنتناوله

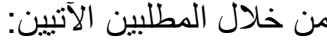

\section{المطلب الأول}

تعريف المركبات الحكومية

المركبة لغةً مأخوذة من فعل ثلاثي مركب، وهو علو علو الثيه، وركب الدابة يركب ركبة ركوباً، علا عليها، فتقول "هذا راكب فرس،

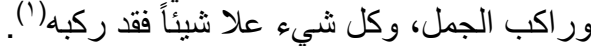

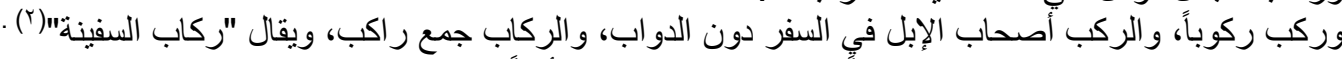

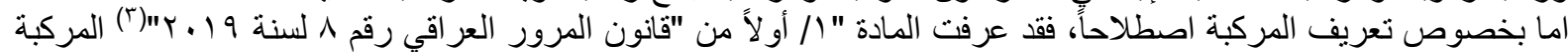
بأنها: "آلة ميكانيكية أو دراجة عادية أو نارية أو عربة أو أي جهاز آخر بسير على الطريق بقوة ميكانيكية أو بأية وسيلة أخرى، الخرك،

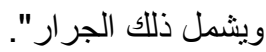

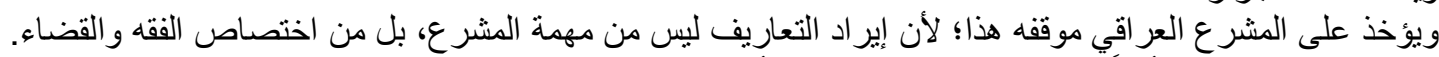

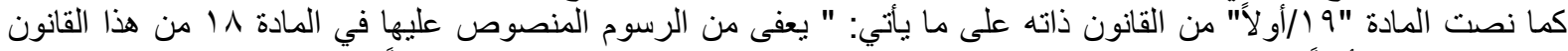

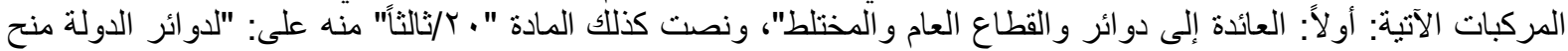
موظفيها وثيقة سوق بالاستناد إلى إجازة السوق الصادرة عن مديرية المرور العامة تخول حاملها قيادة المركبات العائدة لتلكي

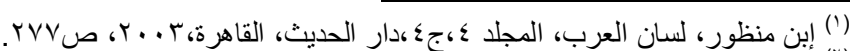

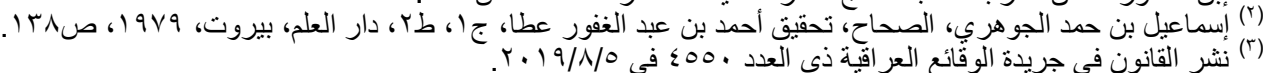


الدائرة وتتناسب مع نوع المركبة"، وجاء في نص المادة "و ب/أولاً" منه: "إذا ارتكب السائق الذي يقود عجلة تعود لدوائر الدولة

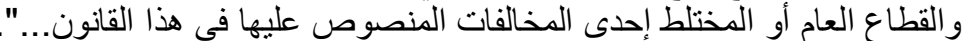

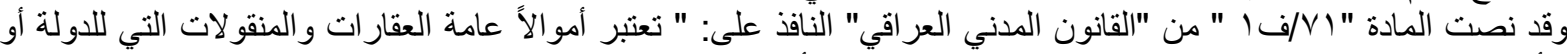

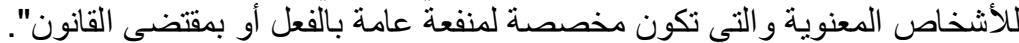

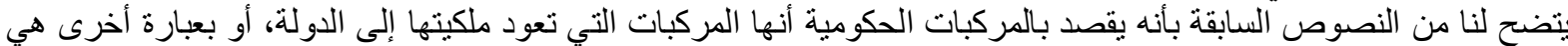

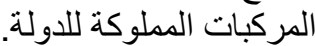

و على هذا الأساس فإن هذه المركبات تختلف عن المركبات الخاصة التي تكون ملكيتها للأفر اد أو الأشخاص المعنوية الخاصةة(')، و هو ما سنبينه في المطلب التالي.

\section{التمييز بين المركبات الحكوميةً وغير الثياتي الحكومية}

قبل بيان معيار التمييز بين المركبات الحكومية وغير الحكومية "المركبات الخاصية"، لابد من الإكية الإشارة إلى معيار التمييز بين الأمو ال العامة والأمو ال الخاصة والذي ظهر بصدئ هما أكثر من معيار ، نبينه في الفروع الآنية الآنية:

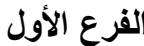

\section{معيار طبيعة المال}

يقوم هذا المعيار على أساس أن الأموال العامة هي تللك التي لا تصلح بطبيعتها لتكون مملوكة ملكية خاصة، وتكون مخصصة

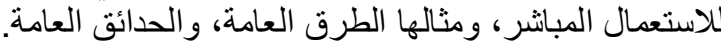

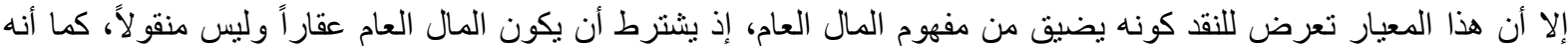

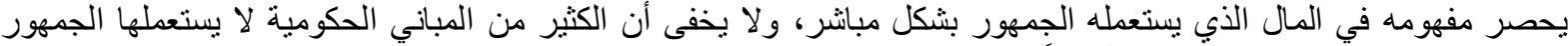
بشكل مباشر ، و لا خلاف في أنها تعد أمو الاً عامة.

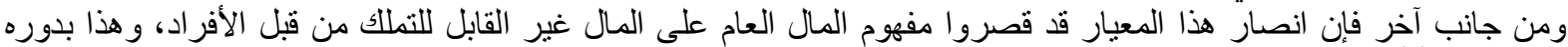

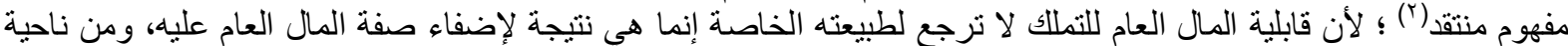

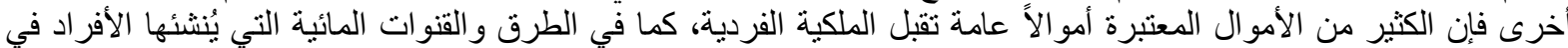
أملاكهم الخاصة.

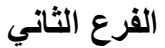

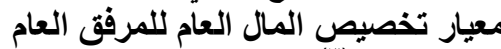

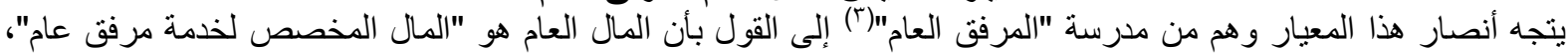

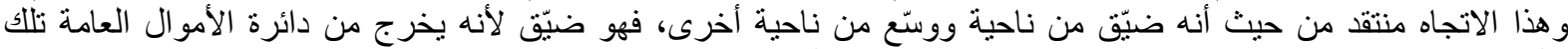

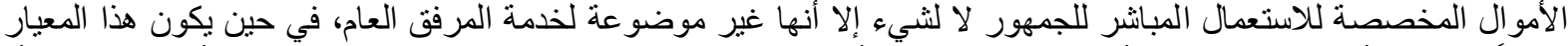

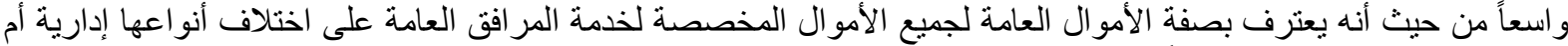

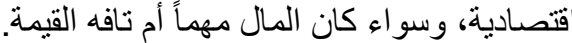

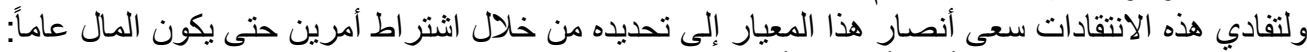
الأول: أن يكون المرفق مرفقاً عاماً جوهرياً.

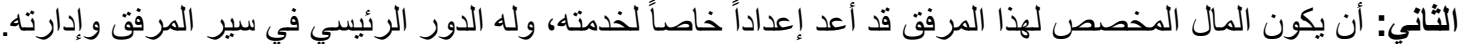

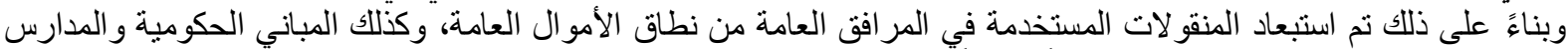

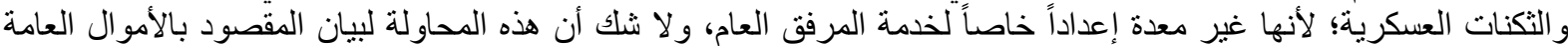

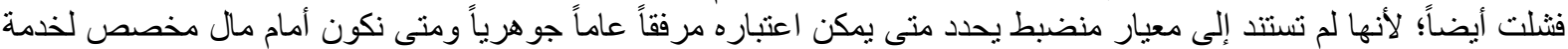

\section{الفرع الثالث}

مرفق عام وله دور رئيس في إندارنه.

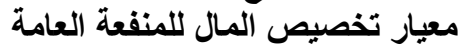

نتيجة للانتقادات الموجهة للمعيارين السابقين، اتجه الفقه نحو الأخذ بمعيار آخر هو المعار معيار تخصيص المعال المال للمنفعة العامة،

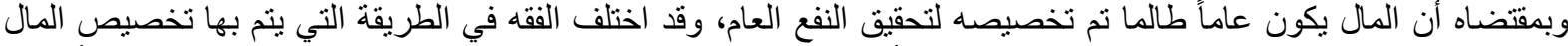

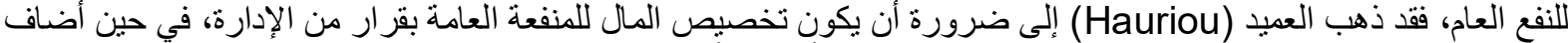
(Waline)

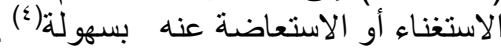

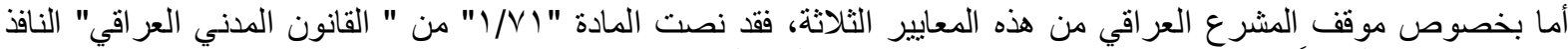

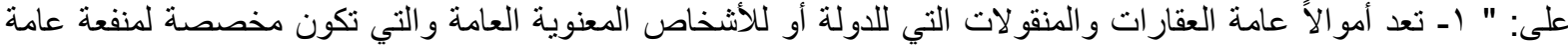

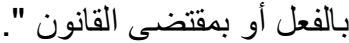
وبموجب هذا النص لاعتبار المال عاماً يجب توفر الثرطين الآتيين :

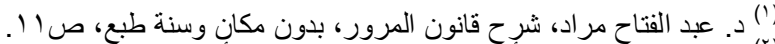

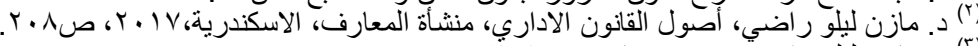

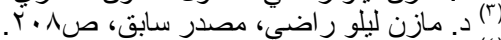

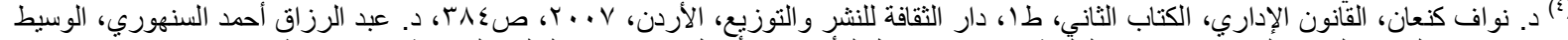

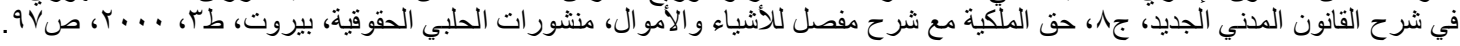




\section{1- ـ أن بكون المال مملوكاً للدولة أو لإحدى الأشخاص المعنوية العامة. \\ r- ب أن يتم تخصيص المال للمنفعة العامة.}

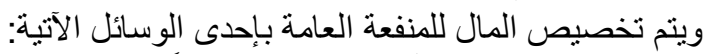

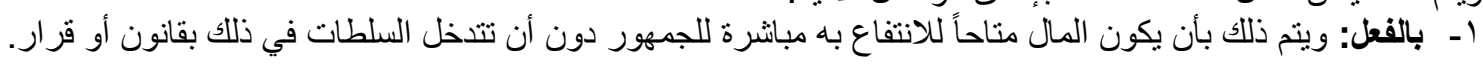

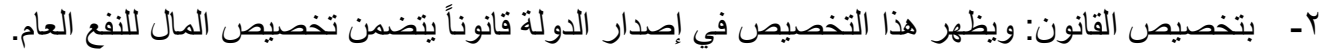

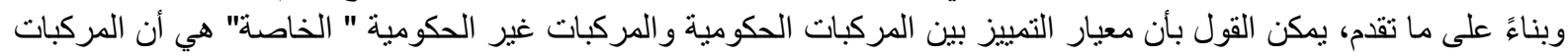

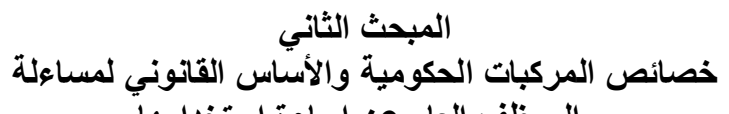

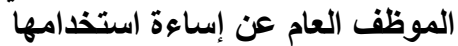

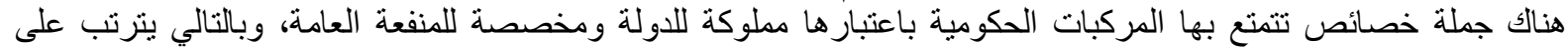

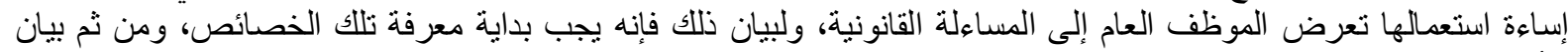

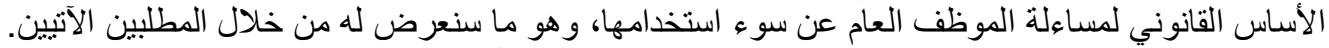

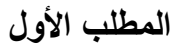

خصائص المركبات المكومية الاول

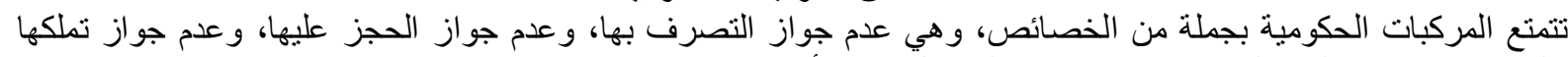

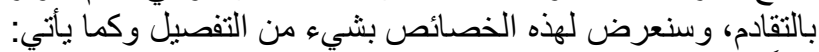

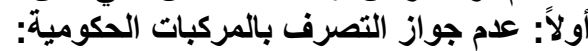

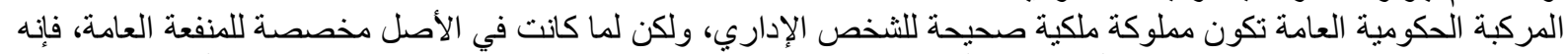

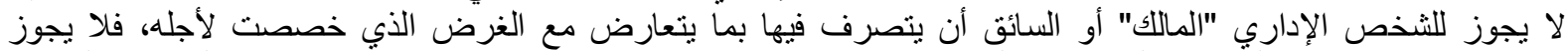

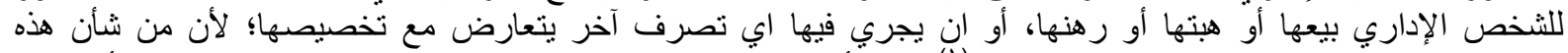

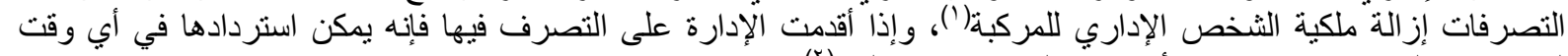

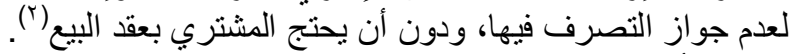

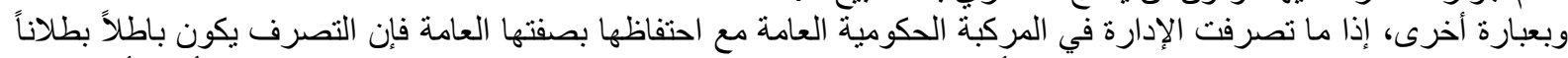

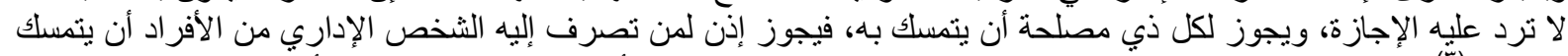

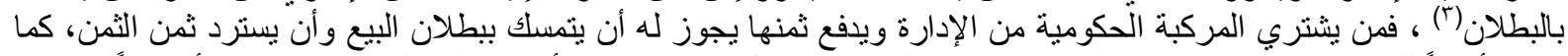

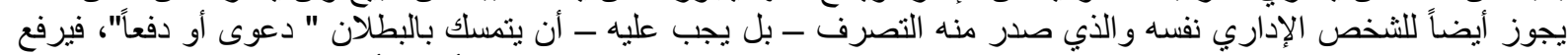

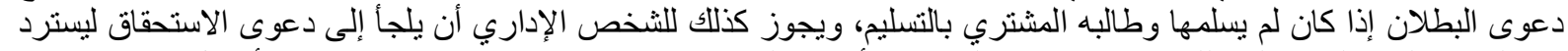

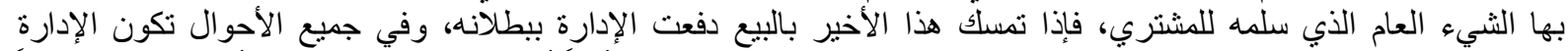

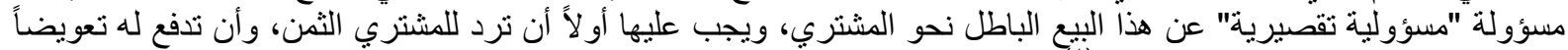

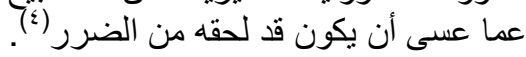

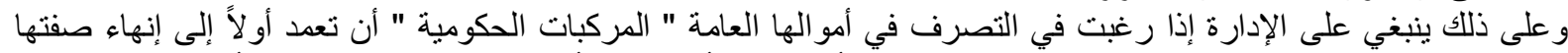

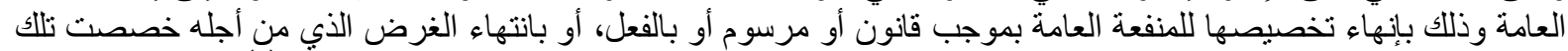

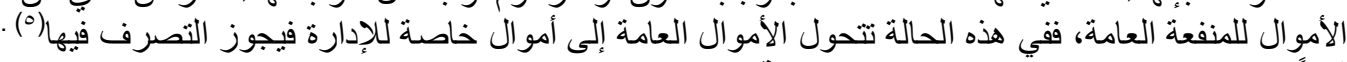

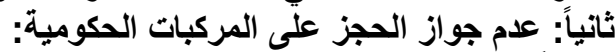

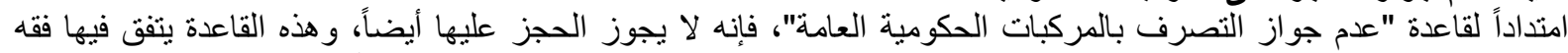

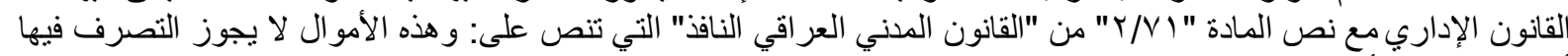
أو الحجز عليها أو تملكها بالتقادم".

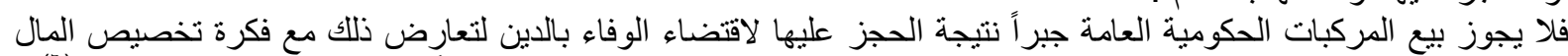

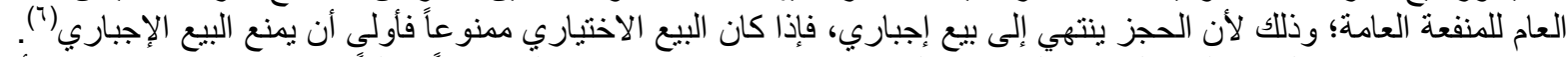

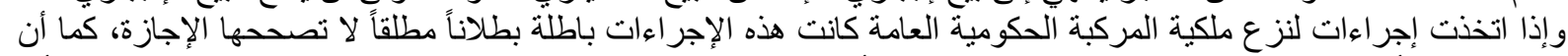

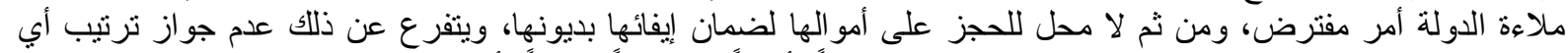

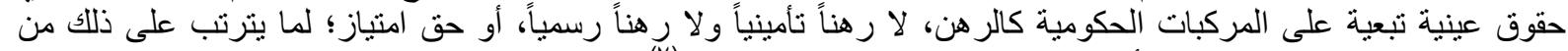

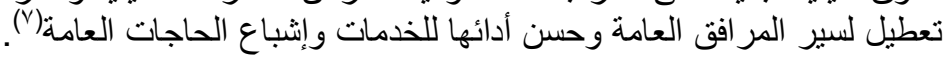

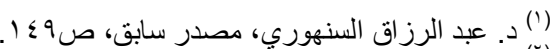

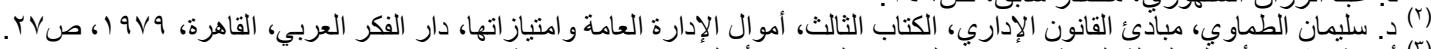

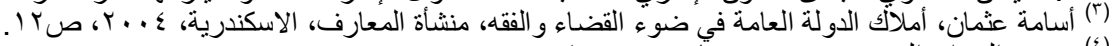

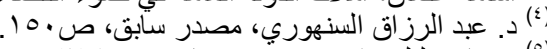

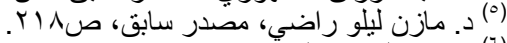

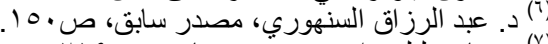

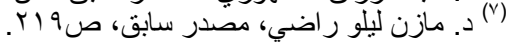


فالحجز هو وسيلة لإجبار المدين وقهره على الوفاء بدينها، فيتم التنفيذ على أمو اله التي يجيز القانون حجز ها ويستوفي الدائن حقه

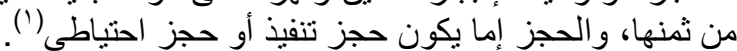

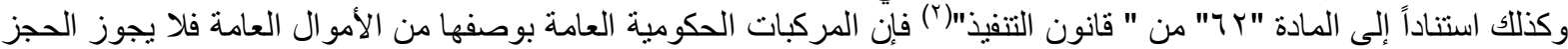

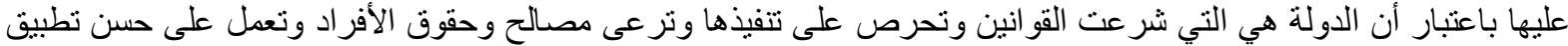

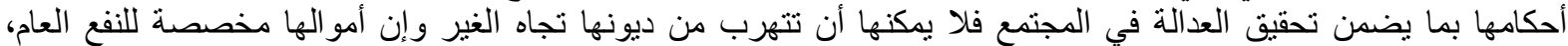

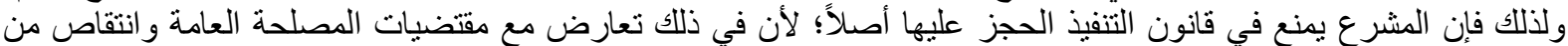

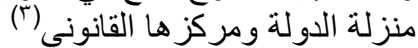

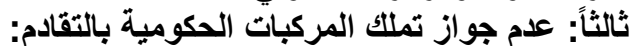

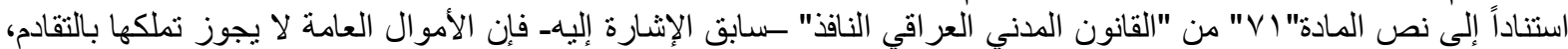

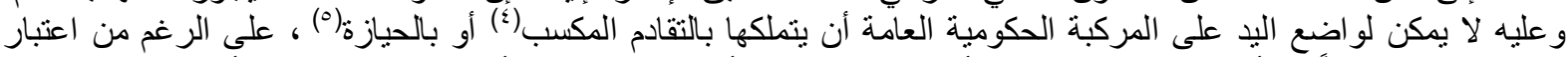

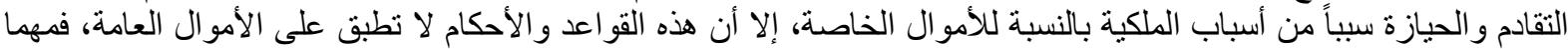

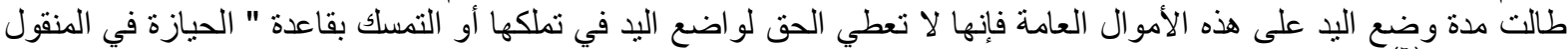

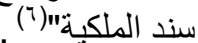

ويجوز للشخص الإداري أن يسترد المركبة الحكومية من يد الحائز ولو كان حسن النية، و إذا كانت المركبة الحكومية قد تعرضت

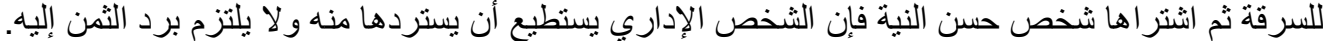

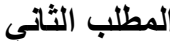

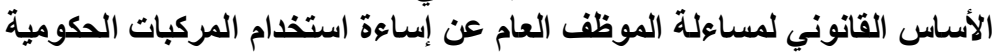

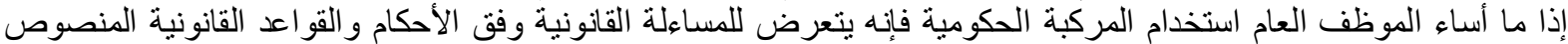

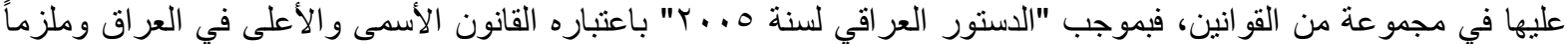

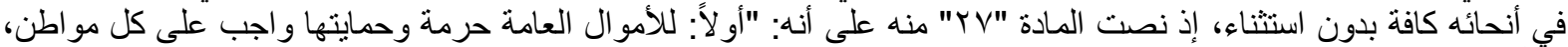

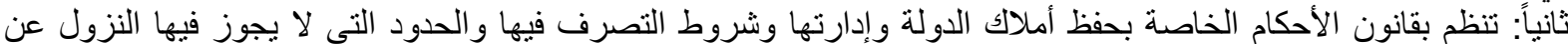

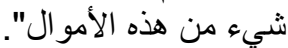

و هذا إن دل على شئ الثيء إنما بيل على ألى أهمية المال العام بصورة عامة والمركبات الحكومية بشكل خاص، مما أدى إلى ارتقاء

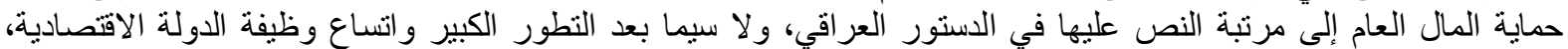

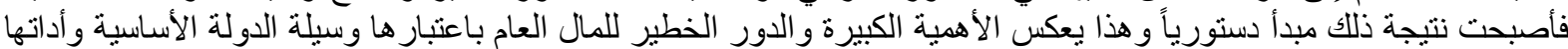

في مباشرة نشاطاتها الاقتصادية.

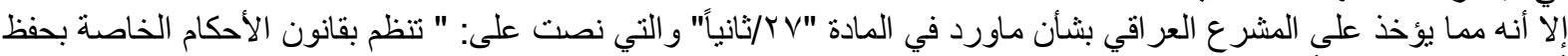

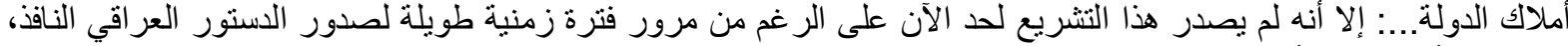

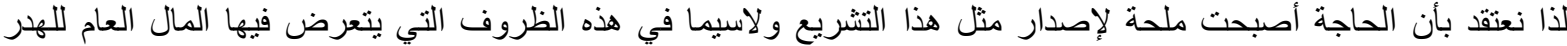

كما أن المركبات الحكومية العامة تحظى بالحماية الإدارية، إذ هناك عقوبات تأديبية منوطة بالإدارة رآها المشرع ضرورية

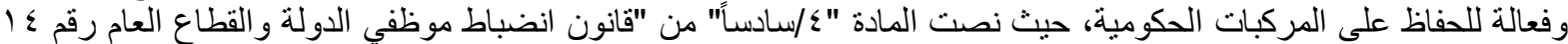

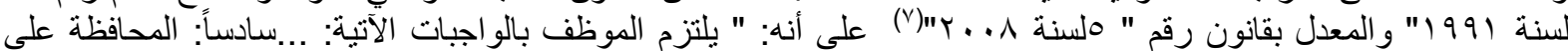

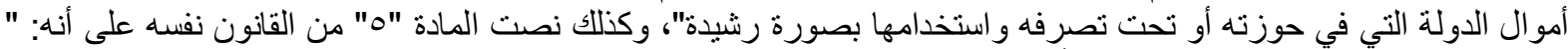

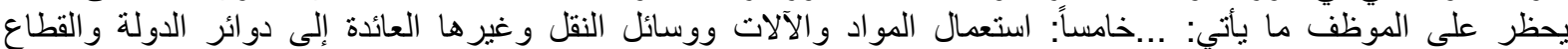

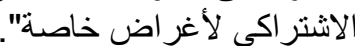

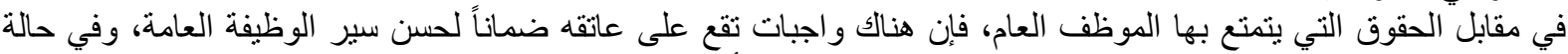

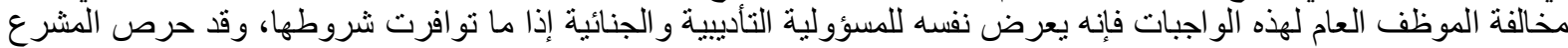

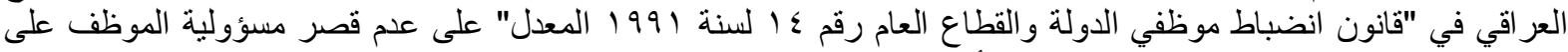

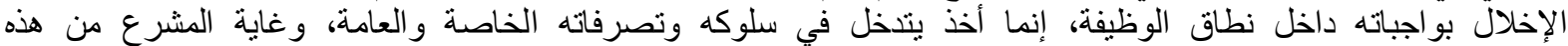

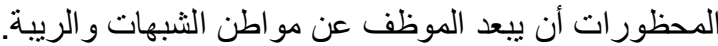

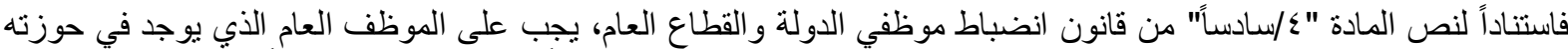

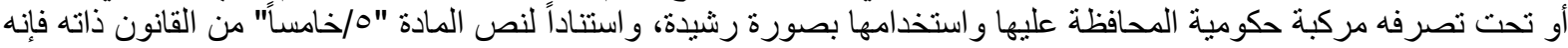

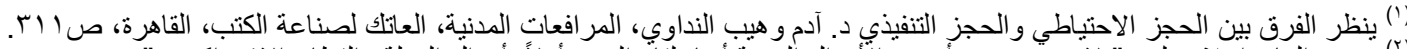

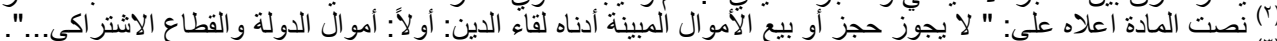

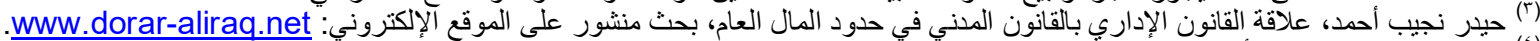

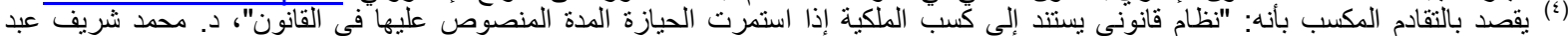

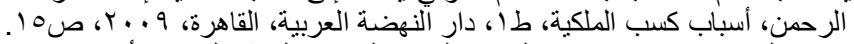

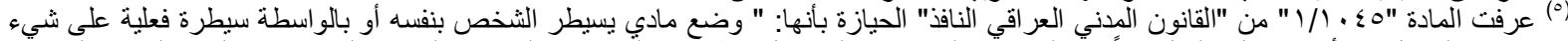

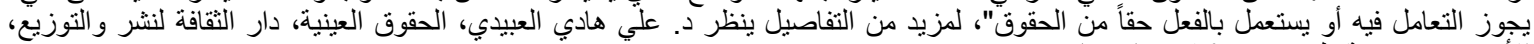

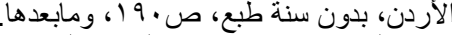

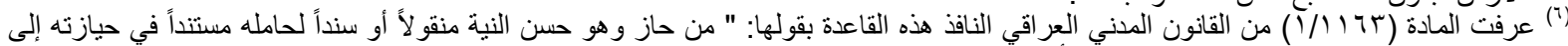




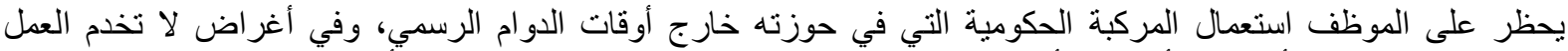

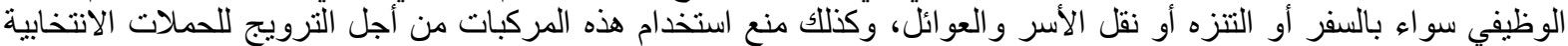

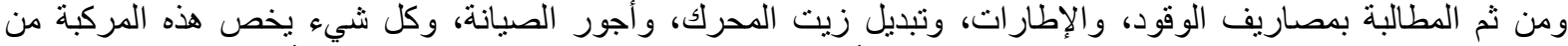

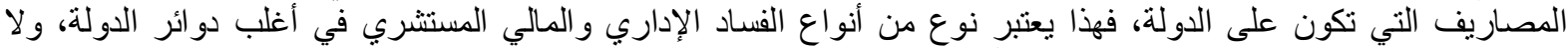

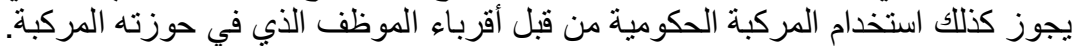

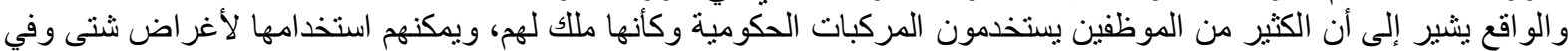

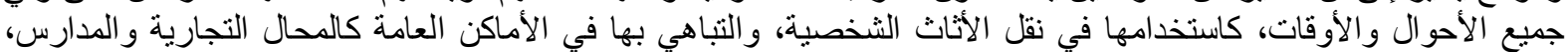

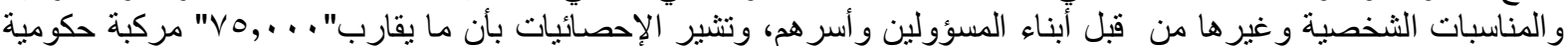

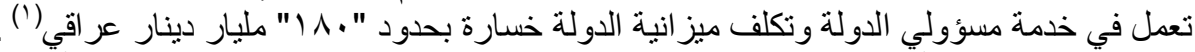

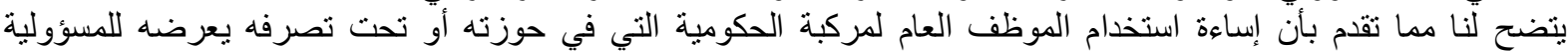

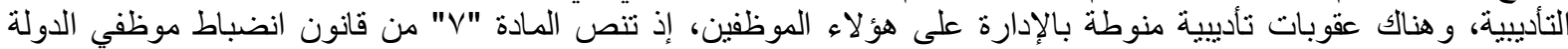

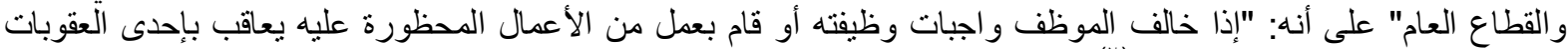

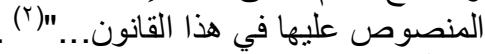

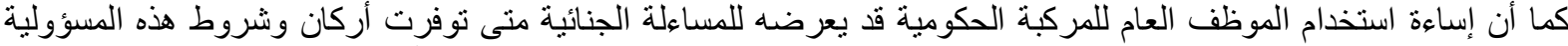

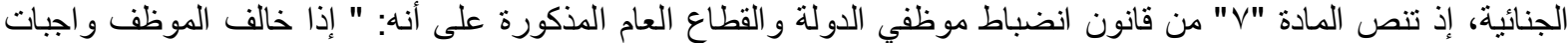

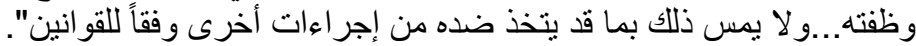

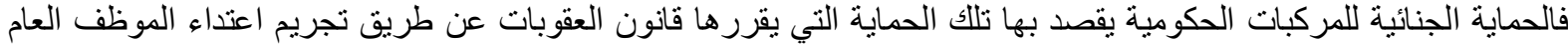

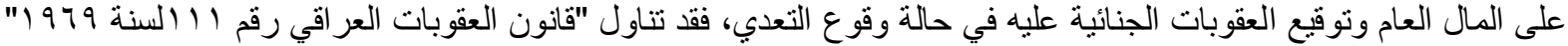

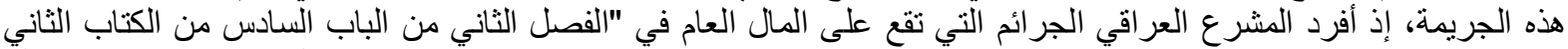

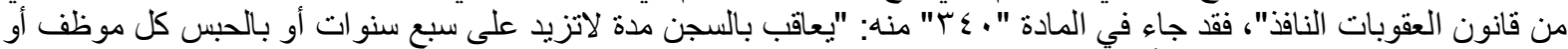

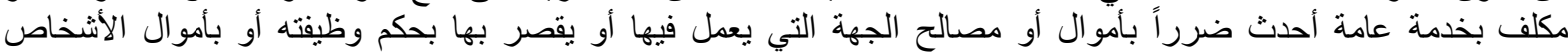

المعهود بها إليه".

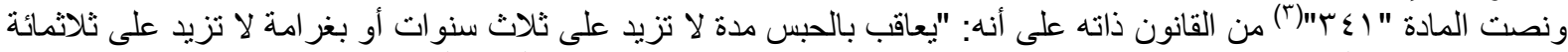

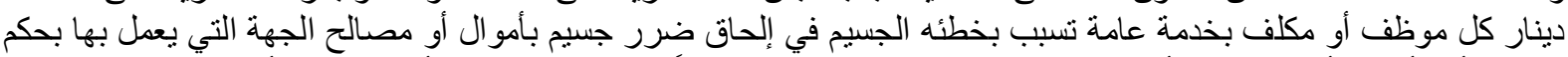

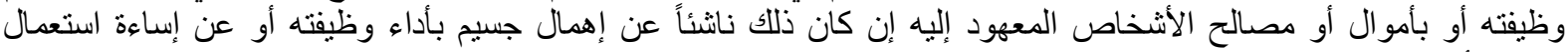

الخاتمة

السلطة أو عن إخلال جسيم بو اجبات وظيفتهه".

بعد الانتهاء من كتابة بحثنا المتو اضع لا بد من الإشارة إلى أهم النتائج و التوصيات التي توصلنا إليها، وكما يأتي:

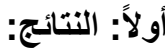

ا- تبين لنا بأن المركبات الحكومية هي المركبات المملوكة للاولة والمخصصة للمنفعة العامة، وهي تختلف عن المركبات

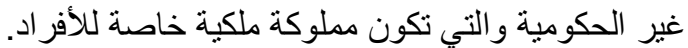

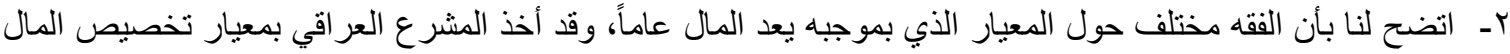

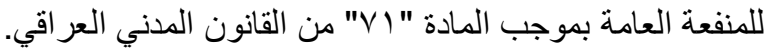

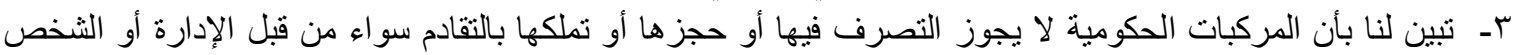

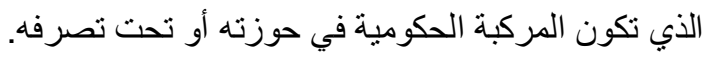

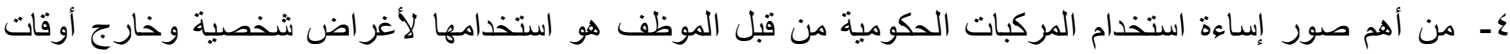

الدوام الرسمي.

0ـ إذا ما أساء الموظف استخدام المركبة الحكومية فإنه يتعرض للمساءلة القانونية سو اء كانت المساءلة تأديبية أو مدنية أو

جنائية.

آ- ألزم الدستور العراقي وقانون العقوبات العراقي وقانون انضباط موظفي الدولة و القطاع العام الموظف العام بالمحافظة

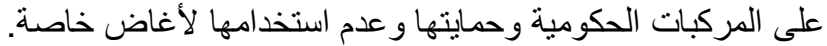

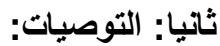

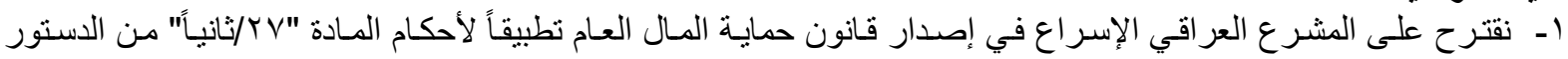

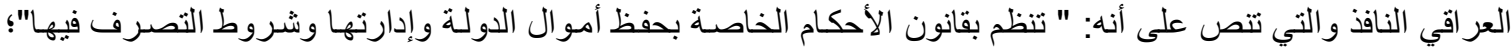

(') الاحصائية مشار إليها في صحيفة المدى تحت عنوان "السيارات الحكمية تستغل لأغراض شخصية" متاح على الموقع الالكتروني http:almadapaper.net (r) لمزيد من التفاصيل حول هذه العقوبات الانضباطية بنظر د. ماهر صالح علاوي، مبادئ القانون الإداري، العاتلك لصناعة الكتب، بدون سنة نثر، 
لأن الحاجة أصبحت ملحة لتشريع هذا القانون لحماية المال العام بشكل عام، و المركبات الحكوميـة بشكل خـاص من الهدر

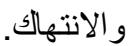

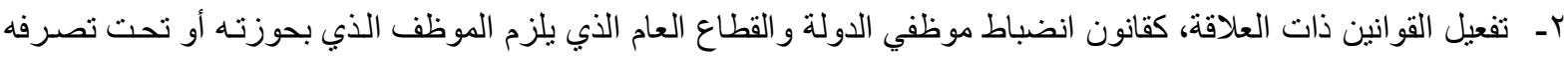

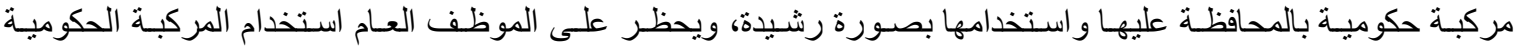

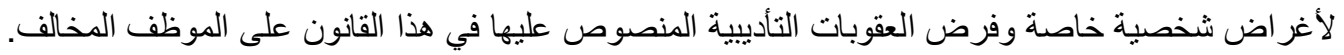

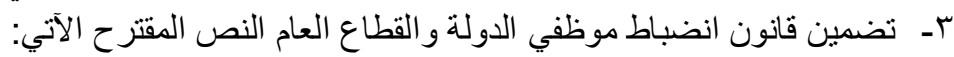

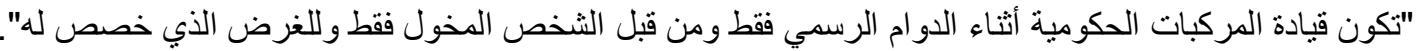
المصادر

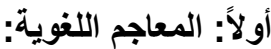

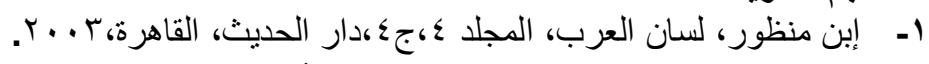

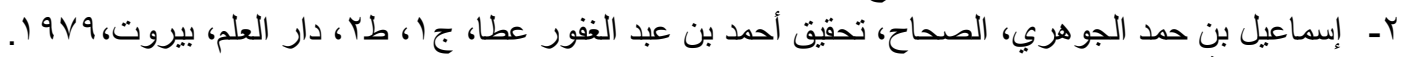

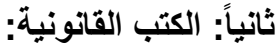

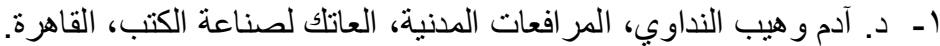

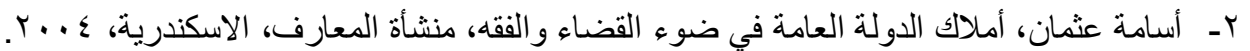

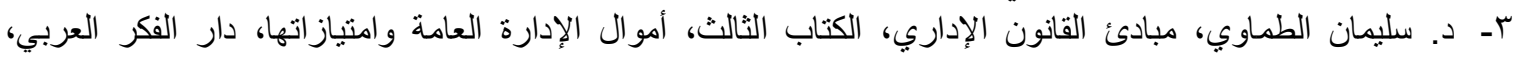

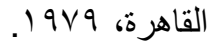
ــ- د. عبد الرزاق أحمد السنهوري، الوسيط في شرح القانون المدني الجديد، جه، حق الملكية مع شرح مفصل للأشياء

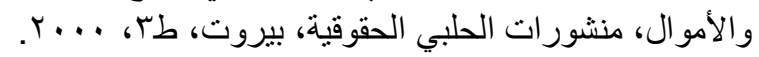

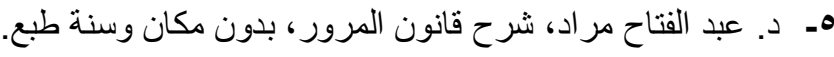

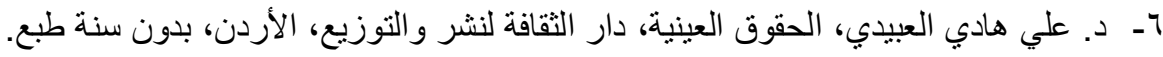

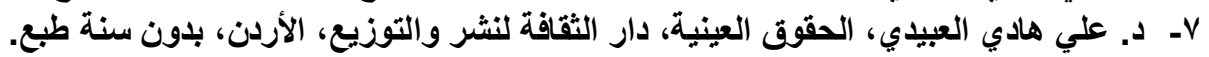

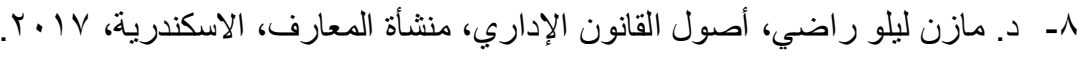

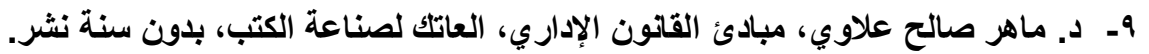

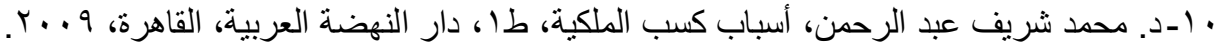

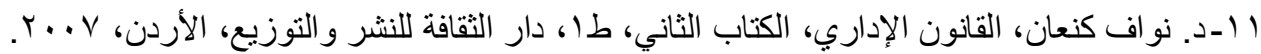

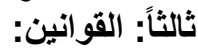

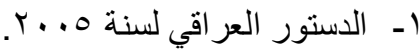

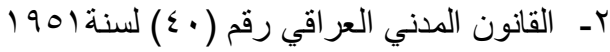

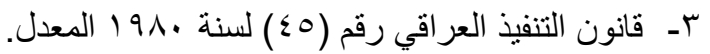

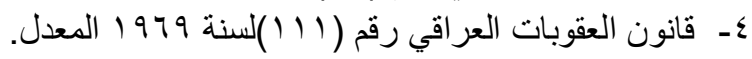

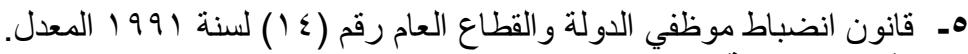

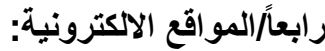
حيدر نجيب أحمد، علاقة القانون الإداري بالقانون المدني في حدود المال العام، بحث منشور على الموقع الإلكتروني:

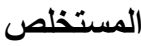

www.dorar-aliraq.net

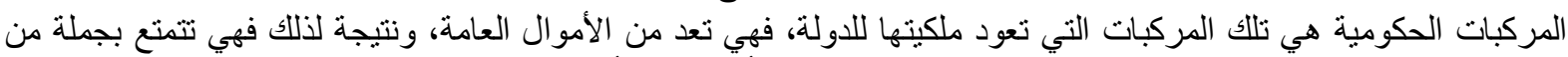

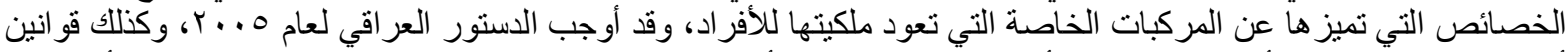

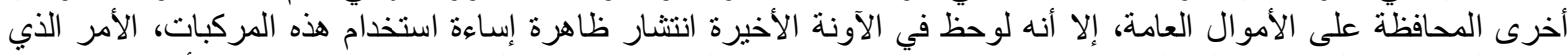

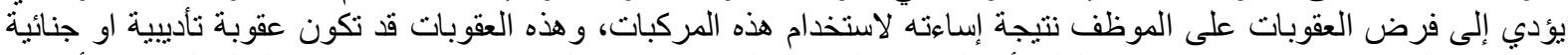

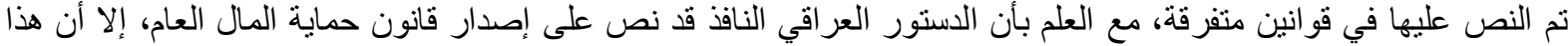




\section{Abstract}

Governmental vehicles are those vehicles that are owned by the state, they are considered public funds, and as a result they have a set of characteristics that distinguish them from private vehicles owned by individuals. The Iraqi constitution of 2005, as well as other laws mandated the preservation of public funds, except that it has been noticed in recent times the phenomenon of misuse of these vehicles, which leads to imposing penalties on the employee as a result of his misuse of these vehicles, and these penalties may be a disciplinary or criminal punishment stipulated in separate laws, bearing in mind that the Iraqi constitution in effect has stipulated an issue Protection of the law of public money, but this law has not been issued so far.

Keywords: Governmental vehicles, public funds, employee. 